\title{
Protective Role of NMDAR for Microwave- Induced Synaptic Plasticity Injuries in Primary Hippocampal Neurons
}

\author{
Hui Wang Shengzhi Tan Li Zhao Ji Dong Binwei Yao \\ Xinping $\mathrm{Xu}$ Bo Zhang Jing Zhang Hongmei Zhou Ruiyun Peng
}

Department of Experimental Pathology, Institute of Radiation Medicine, Academy of Military Medical

Sciences, Beijing, China

\section{Key Words}

Microwave radiation $\cdot$ NMDAR $\cdot$ Synaptic plasticity $•$ Primary hippocampal neurons

\begin{abstract}
Background/Aims: The N-methyl-D-aspartic acid receptor (NMDAR) has been extensively studied for its important roles in synaptic plasticity and learning and memory. However, the effects of microwave radiation on the subunit composition and activity of NMDARs and the relationship between NMDARs and microwave-induced synaptic plasticity have not been thoroughly elucidated to date. Materials: In our study, primary hippocampal neurons were used to evaluate the effects of microwave radiation on synaptic plasticity. Structural changes were observed by diolistic (Dil) labeling and scanning electron microscopy (SEM) observation. Functional synaptic plasticity was reflected by the NMDAR currents, which were detected by whole cell patch clamp. We also detected the expression of NMDAR subunits by real-time PCR and Western blot analysis. To clarify the effects of microwave radiation on NMDARinduced synaptic plasticity, suitable agonists or inhibitors were added to confirm the role of NMDARs on microwave-induced synaptic plasticity. Dil labeling, SEM observation, whole cell patch clamp, real-time PCR and Western blot analysis were used to evaluate changes in synaptic plasticity after treatment with agonists or inhibitors. Results: Our results found that microwave exposure impaired neurite development and decreased mRNA and protein levels and the current density of NMDARs. Due to the decreased expression of NMDAR subunits after microwave exposure, the selective agonist NMDA was added to identify the role of NMDARs on microwave-induced synaptic plasticity injuries. After adding the agonist, the expression of NMDAR subunits recovered to the normal levels. In addition, the microwave-induced structural and functional synaptic plasticity injuries recovered, including the number and length of neurites, the connections between neurons, and the NMDAR current. Conclusion: Microwave radiation caused neuronal synaptic plasticity injuries in primary hippocampal neurons, and NMDARs played protective roles on the damage process.

(C) 2018 The Author(s)

Published by S. Karger AG, Basel

$\mathrm{H}$. Wang and S. Tan contributed equally to this work.

\begin{tabular}{ll}
\hline Prof. Ruiyun Peng, PhD & Beijing Institute of Radiation Medicine \\
& 27 Taiping Road, Beijing (China) \\
& Tel. +86106693 1236, E-Mail ruiyunpeng18@126.com; pengry@bmi.ac.cn
\end{tabular}
\end{abstract}




\section{Cellular Physiology Cell Physiol Biochem 2018;51:97-112

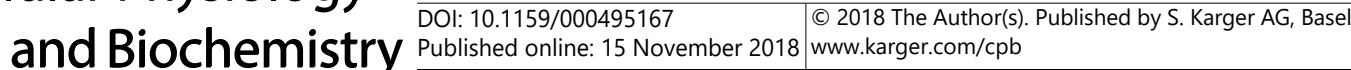 \\ Wang et al.: Effects of Microwave on Synaptic Plasticity and NMDAR}

\section{Introduction}

Microwave technology is widely used in many fields, such as telecommunications, medical treatments, and military applications. The effects of microwave radiation on the central nervous system (CNS) have attracted the attention of many scholars [1-3]. However, the underlying mechanisms have not yet been evaluated. The N-methyl-D-aspartic acid receptor (NMDAR) is a type of glutamate-gated ion channel that is pivotal to the regulation of synaptic plasticity in the CNS[4]. The subunit composition of NMDARs in neurons affects channel activity and downstream signaling [5]. Our study group previously found that the expression levels of NMDAR subunits were associated with microwave-induced learning and memory impairments in a long-term, observational study on Wistar rats [6]. Other studies have also shown that microwave radiation could impair synaptic plasticity and cause structural and functional injuries through the NMDAR signaling pathway. Acute or chronic microwave exposure also caused changes in the $\mathrm{K}_{d}$ and $\mathrm{B}_{\max }$ values of NMDARs and reduced the excitatory synaptic activity in the brain and in cultured hippocampal neurons $[7,8]$. However, the effects of microwave radiation on the subunit composition and activity of NMDARs and their relationship with microwave-induced synaptic plasticity are still not understood.

Primary hippocampal neurons are more representative and persuasive than other cell lines, such as PC12 cells, for revealing the mechanism of neuronal injuries in in vitro studies. Synaptic plasticity includes both structural and functional aspects. The relationship between synaptic plasticity and NMDARs has been evaluated exhaustively [4, 9-11]. Therefore, we intended to use primary hippocampal neurons to explore the roles of NMDARs in microwaveinduced structural and functional plasticity changes.

The observation of neuronal morphology is a key component to understanding neuronal functions [12]. Diolistic labeling (Dil labeling) is increasingly utilized in neuroscience as an efficient, reproducible method for the visualization of neuronal morphology. Dil is a nontoxic, fluorescent labeling method that can label multiple neurons in both living and fixed cells or tissues [13]. Moreover, the Sholl analysis is a method of quantitative analysis that has been commonly used in neuronal studies to characterize the morphological characteristics of an imaged neuron $[14,15]$. Dil labeling, combined with the Sholl analysis, could better explain the effects of microwave radiation on the development of neurites. To better clarify structural changes, scanning electron microscopy (SEM), which can be used to observe the surface microstructure, has also been applied to visualize connections between neurites.

Functional synaptic plasticity is another important aspect for understanding microwaveinduced injuries in neurons. NMDARs could interact with presynaptic glutamate and become activated. Moreover, the subunit composition of NMDARs is plastic, resulting in a large number of receptor subtypes. To date, seven different subunits, divided into three subfamilies according to sequence homology, have been identified: GluN1, GluN2 (A, B, C and D) and GluN3 (A and B) [16, 17]. Among the seven subunits, the GluN1, GluN2A and GluN2B subunits have been found to be closely related to microwave-induced synaptic plasticity [6]. Moreover, calcium influx through NMDARs at excitatory synapses could activate downstream signaling pathways and participate in synaptic plasticity via the activation of $\mathrm{Ca}^{2+} /$ calmodulindependent protein kinase type II (CaMKII) and its translocation to the GluN2B subunit of NMDA receptor. The major binding site for CaMKII on GluN2B undergoes phosphorylation at Ser 1303 [18]. Therefore, it is necessary to determine the expression levels of NMDAR subunits. With the development of patch clamp, the most direct and effective method for evaluating the activation of NMDARs is by recording electric activity, such as changes in the current amplitude or density.

In summary, first, we intended to evaluate the effects of microwave radiation on structural and functional plasticity and the expression and activation of NMDARs to determine whether microwave radiation can induce synaptic plasticity injuries and NMDAR changes. Next, the suitable agonists or inhibitors were added to confirm the role of the NMDAR on microwaveinduced synaptic plasticity. 


\section{Cellular Physiology Cell Physiol Biochem 2018;51:97-112

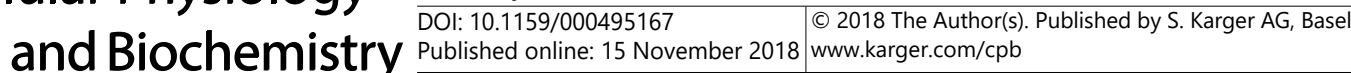

Wang et al.: Effects of Microwave on Synaptic Plasticity and NMDAR

\section{Materials and Methods}

\section{Cell preparations and microwave exposure}

Wistar rats at postnatal ages of younger than $12 \mathrm{~h}$ were purchased from the Experimental Animal Center of Beijing Institute of Radiation Medicine (Beijing, China). All protocols were approved by the Institutional Animal Care and Use Committee. Primary hippocampal neuron cultures were prepared as described previously, with some modifications [19]. Briefly, the hippocampi were microdissected under a dissecting microscope (Motic China group Co., LTD, China) and then digested with $0.25 \%$ trypsin-EDTA (Gibco, USA) at $37^{\circ} \mathrm{C}$ for $20 \mathrm{~min}$. The cells were suspended with DMEM, containing $10 \%$ fetal bovine serum (Gibco, USA), 10 $\%$ horse serum (Gibco, USA), $1 \%$ L-glutamine (Invitrogen, USA) and $1 \%$ penicillin-streptomycin solution (HyClone, USA), and plated at a density of $5 \times 10^{5} / \mathrm{ml}$ on poly-D-lysine (Sigma, USA)-coated $35 \mathrm{~mm}$ dishes, glass coverslips or $15 \mathrm{~mm}$ glass bottom cell culture dishes. At $24 \mathrm{~h}$ after plating, the plating medium was replaced with DMEM containing $10 \%$ horse serum, $1 \%$ L-glutamine, $1 \%$ penicillin-streptomycin solution, $2 \% \mathrm{~B} 27$, and $1 \% \mathrm{~N} 2$. To inhibit the growth of glial cells, $3 \mu \mathrm{g} / \mathrm{ml}$ cytarabine (Sigma, USA) was added at DIV 3 after plating. Then, half of the medium was changed $24 \mathrm{~h}$ after adding cytarabine. Afterward, half of the medium was changed every four days.

The cells were randomly divided into the control group (C) and the radiation group (R). The radiation group was exposed to microwaves with an average power density of $50 \mathrm{~mW} / \mathrm{cm}^{2}$ for $6 \mathrm{~min}$. The source of microwave exposure has been described in detail in our early published article [20]. Briefly, the primary parameters for the radiation group were as follows. The repetition frequency was $500 \mathrm{pps}$, the pulse width was $500 \mathrm{~ns}$, and the peak field power density was $200 \mathrm{~W} / \mathrm{cm}^{2}$. Moreover, the output power of the radiation source was 1.4 MW. The control group was treated in the same location for 6 min but without microwave exposure.

\section{Dil labeling and Image analysis}

The cells in the confocal dishes were randomly divided into $\mathrm{C}$ and R groups. At DIV 7, the cells in the $\mathrm{R}$ group were exposed to microwave radiation. At DIV 8 and 12 (at 1 and $5 \mathrm{~d}$ after microwave exposure), the cells were treated with Dil labeling, which was adapted from previously described methods [21]. Briefly, the vibrant Dil cell-labeling solution (Life Technologies, USA) was diluted 200 times with sterile phosphatebuffered saline (PBS) and added to the confocal dishes for $30 \mathrm{~min}$ at $37^{\circ} \mathrm{C}$. Then, the labeling solution was removed, and the dishes were washed three times for $10 \mathrm{~min}$ with $\mathrm{PBS}$ at $37^{\circ} \mathrm{C}$.

Afterwards, cultures were maintained in the recording chamber of a LSM 880 confocal laser scanning microscope (CLSM) (Carl Zeiss, German) at $37^{\circ} \mathrm{C}$ with $5 \% \mathrm{CO}_{2}$. The images were captured randomly with a $40 \times$ objective lens and analyzed with ImageJ software (National Institutes of Health, USA). Plugins named Neuron J and Sholl Analysis were downloaded and installed under ImageJ for subsequent analyses. First, all images were transferred to 8-bit pictures and the brightness and contrast were adjusted to ensure all branches were visible and to avoid the occurrence of dye sediments. Then, Neuron J was used to add tracings and to measure all branches on each neuron. The Sholl analysis parameters were set as follows to measure the number of branches. The starting radius, ending radius, radius step size and radius span were set to 5 , 150,5 and $1 \mu \mathrm{m}$, respectively.

\section{SEM observation}

Cell climbing sheets were exposed at DIV 7 and gathered for SEM observation at DIV 12. After washed with PBS buffer, the climbing sheets were fixed with $2.5 \%$ glutaraldehyde and then rinsed with sucrose PBS buffer. After fixation with osmium acid, all samples were dehydrated with an ethanol gradient and treated with isoamyl acetate for $25 \mathrm{~min}$. Then, hexamethyldisilazane was used to dry the samples, which were then adhered to an insulating gel and sprayed with gold for observation by S-3400 SEM (Hitachi HighTechnologies, Japan).

\section{Real-time PCR}

The primary hippocampal neurons were exposed to microwave radiation at DIV 7 and collected at 1, 6, 12 and $24 \mathrm{~h}$ after microwave exposure for total RNA extraction using Trizol (Invitrogen, USA). The sequences of the gene-specific primers for GluN1, GluN2A and GluN2B and GAPDH were those described in Xiong's methods [22]. In addition, the reverse transcriptase polymerase chain reaction (RT-PCR) and real- 


\section{Cellular Physiology Cell Physiol Biochem 2018;51:97-112

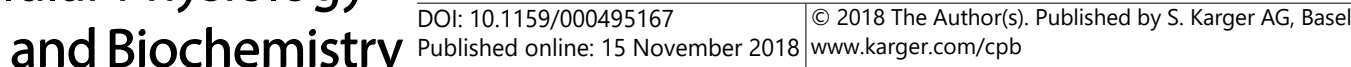

time PCR were performed according to Xiong's methods. Gene expression was calculated as the ratio of the experimental group to the control group.

\section{Western Blot Analysis}

Microwave exposure was conducted at DIV 7 and protein expression was detected at 6 and $24 \mathrm{~h}$. Total protein was extracted form primary hippocampal neurons using RIPA buffer containing protease inhibitor. Samples containing $30 \mu \mathrm{g}$ protein were separated by $8 \%$ sodium dodecyl sulfate-polyacrylamide gel electrophoresis (SDS-PAGE) and transferred to polyvinylidene difluoride (PVDF) membranes (Millipore, USA). After blocking with $5 \%$ nonfat milk for $1 \mathrm{~h}$, the PVDF membranes of corresponding molecular weights were incubated overnight at $4^{\circ} \mathrm{C}$ with the following primary antibodies: anti- GluN1 (goat monoclonal 1:1, 000, Abcam, USA), anti-GluN2A, anti-GluN2B and anti-p-GluN2B (phosphor S1303) (rabbit monoclonal 1:1, 000, Abcam, USA), anti-GAPDH (mouse monoclonal 1:1, 000, Abcam, USA). The secondary antibodies were HRP-conjugated anti-goat, rabbit or mouse antibodies (1:5, 000, Zhongshan Biotechnology, China). The relative densities were semiquantitatively analyzed using ImageJ software.

\section{Whole-cell recordings of NMDAR currents}

NMDAR currents were recorded as described previously, with some modifications [7, 23]. The current responses $\left(I_{\mathrm{NMDA}}\right)$ were elicited in cultured hippocampal neurons (DIV 7-10) perfused with NMDA. The recording patch pipettes were made with a pipette puller (P-97, Sutter Instrument Company, USA), with the resistances of 5-7 M $\Omega$. The internal solution contained $140 \mathrm{mM} \mathrm{K}$-Gluconate, $10 \mathrm{mM} \mathrm{KCl,} 3 \mathrm{mM}$ EGTA, $2 \mathrm{mM}$ Mg-ATP, $0.2 \mathrm{mM} \mathrm{Na-GTP}$ and $10 \mathrm{mM}$ HEPES (pH 7.2, adjusted with $1 \mathrm{M} \mathrm{CsOH}$, and osmolarity 300310 mOsm, adjusted with sucrose). The bath solution contained $150 \mathrm{mM} \mathrm{NaCl}, 3 \mathrm{mM} \mathrm{KCl}, 3 \mathrm{mM} \mathrm{CaCl}, 10$ mM Glucose and $10 \mathrm{mM}$ HEPES (pH 7.3, adjusted with $1 \mathrm{M} \mathrm{NaOH}$, and osmolarity 300-310 mOsm, adjusted with sucrose). The K-Gluconate, EGTA, Mg-ATP, Na-GTP, HEPES, CsOH and NMDA were purchased from the Sigma-Aldrich company, and the rest of the reagents were purchased from Sinopharm Chemical Reagent, Co., Ltd, China.

The Multiclamp 700B amplifier, Digidata 1440A converter and pClamp 10 software (Axon Instruments, USA) were used to record the whole cell currents. The membrane potential was held at $-70 \mathrm{mV}$.

The application of NMDA $(300 \mu \mathrm{M})$ onto primary hippocampal neurons was conducted by the Picospritzer III pressure drug application system (Parker, USA), which was connected with high purity nitrogen. The glass tubes for adding NMDA were pulled from OD $1.0 \mathrm{~mm}$ borosilicate glass and placed 200 $\mu \mathrm{m}$ away from the recorded cell. The pulling parameters were as follows: heat 569 , pull 0 , vel 12 , and time 250. The time of drug application was set as $1 \mathrm{~s}$. After adding the NMDA by a drug pipette, a negative current was recorded.

To verify that the negative current was $I_{N M D A}$, the specific inhibitor AP-5 $(100 \mu \mathrm{M})$ was added to the recording dish by pipette. After a few seconds of diffusion by stirring the liquid through the pipette tip, a negative current could not be recorded by adding NMDA (300 $\mu \mathrm{M})$ (Fig. 1). In the formal experiments, to evaluate the effects of microwave radiation on $I_{N M D A}$, there was no need to add AP-5.

All recordings were conducted immediately after microwave exposure. To avoid errors caused by different sized cells, the current density $\left(\mathrm{I}_{\mathrm{d}}\right)$ was used as the analysis indicator. $\mathrm{I}_{\mathrm{d}}=\mathrm{I}_{\mathrm{m}} / \mathrm{C}_{\mathrm{m}}(\mathrm{pA} / \mathrm{pF})$.

\section{Regulation of NMDAR}

The selective agonist NMDA was added to observe the regulatory role of NMDAR on synaptic plasticity in hippocampal neurons. The concentration of NMDA was set to $30 \mu \mathrm{M}$. In this section, four groups were used: $0 \mathrm{~mW} / \mathrm{cm}^{2}(\mathrm{C}), 50 \mathrm{~mW} /$ $\mathrm{cm}^{2}(\mathrm{R})$, the control group with $30 \mu \mathrm{M}$

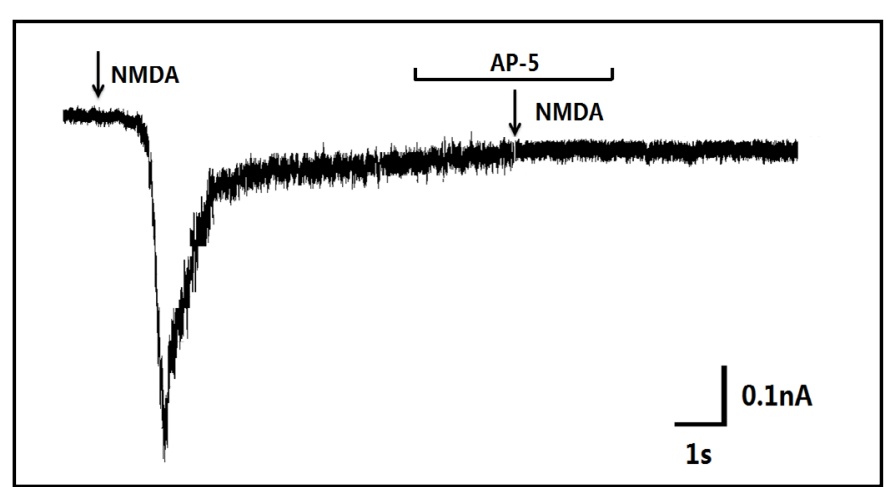

Fig. 1. Identification of $\mathrm{I}_{\mathrm{NMDA}}$ in primary hippocampal neurons. The negative current was recorded after adding NMDA and inhibited by AP-5. 


\section{Cellular Physiology Cell Physiol Biochem 2018;51:97-112

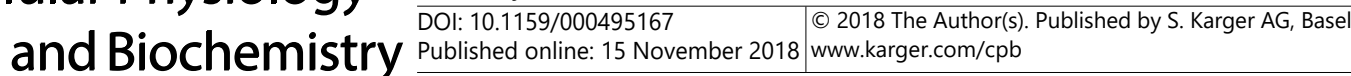 \\ Wang et al.: Effects of Microwave on Synaptic Plasticity and NMDAR}

NMDA (C+NMDA), and the exposure group with $30 \mu \mathrm{M}$ NMDA (R+NMDA). NMDA was added at $1 \mathrm{~h}$ before microwave exposure each time, and then the cells were washed and recovered with fresh medium. The cells were collected for Dil-staining, SEM observation, Western blot analysis, real time PCR and patch clamp. The observation time was at $5 \mathrm{~d}$ for Dil-staining and SEM observation. Real time PCR was detected $12 \mathrm{~h}$ after microwave exposure, and the Western blot analysis was performed $24 \mathrm{~h}$ after microwave exposure. The patch clamp was conducted immediately after microwave exposure. The observation times were chosen according to the results of the effects of microwave exposure on synaptic plasticity. Most observation time points were chosen to study the regulatory roles of NMDAR on microwave-induced synaptic plasticity injuries.

\section{Statistical analysis}

To compare the differences between the $\mathrm{C}$ and $\mathrm{R}$ groups, a two-way analysis of variance (ANOVA) was applied. A $2 \times 2$ factorial design was applied to determine the regulatory role of the agonist on synaptic plasticity. The software used was SPSS 19. Multiple comparisons were performed by the SNK analysis. Differences at $\mathrm{p}<0.05$ were considered to be significant.

\section{Results}

\section{NMDAR participated in microwave-induced synaptic plasticity injuries}

Microwave exposure induced the impairment of neurite development. Dil-staining was conducted 1 and $5 \mathrm{~d}$ after microwave exposure to observe the effects of microwave exposure on neurite development. The statistical results were shown for each time point. After $1 \mathrm{~d}$, the lengths of neurites showed no significant shortness, and the number of branches on the neurons did not decrease (Fig. 2A and B and Fig. 3). However, $5 \mathrm{~d}$ after microwave exposure, the lengths of the neurites in the R group were significantly decreased when compared with those of the $\mathrm{C}$ group (Fig. $2 \mathrm{C}$ and D and Fig. $3 \mathrm{~A})\left({ }^{*} \mathrm{p}<0.05\right)$. Moreover, the whole group effect for the $\mathrm{C}$ and $\mathrm{R}$ groups were also evaluated. There were no interaction effects between microwave exposure and observation time. The results showed significant differences between the two groups for the lengths and numbers of neurites (Fig. 3) $(\Delta \mathrm{p}<0.05)$. In the Sholl analysis, the number of neurites $15 \mu \mathrm{m}$ from the centers of the cell bodies decreased significantly in the $R$ group 5 $\mathrm{d}$ after microwave exposure (Fig. 3B) $\left({ }^{*} \mathrm{p}<0.05\right)$, indicating a developmental disorder in proximal neurites after microwave exposure. Moreover, to observe slight changes in neurites, SEM observation was conducted $5 \mathrm{~d}$ after microwave exposure. Proximal fractures were observed in the $\mathrm{R}$ group (Fig. 4).

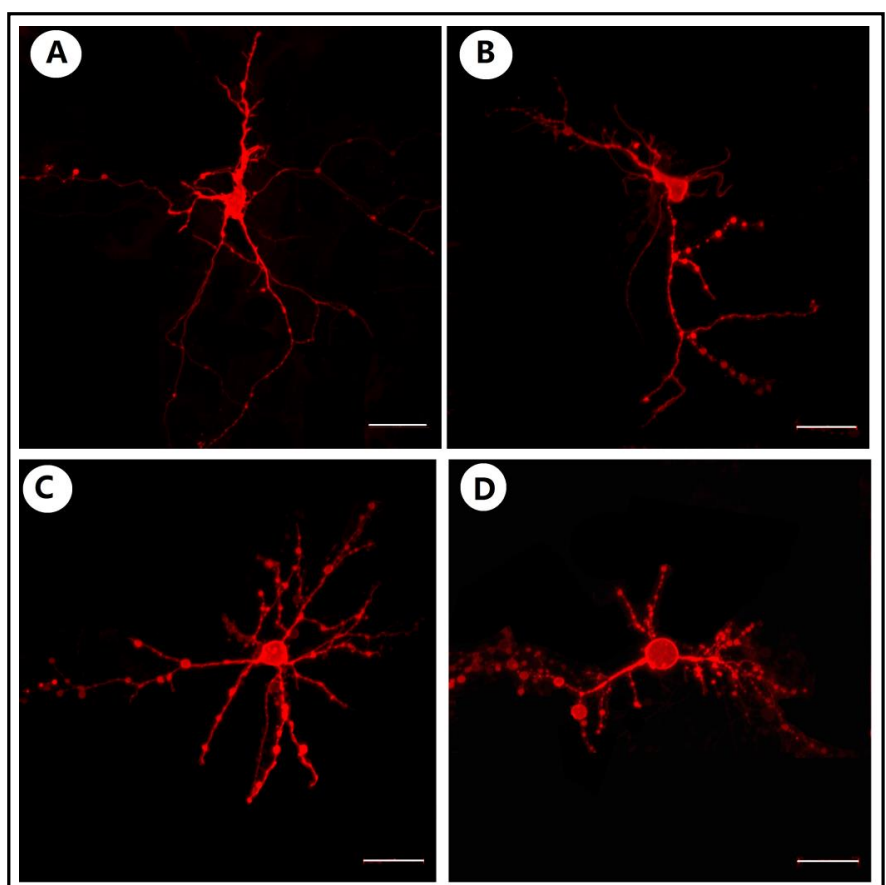

Fig. 2. Structure of hippocampal neurons by Dil-staining 1 and 5 $\mathrm{d}$ after microwave exposure. A-B: $1 \mathrm{~d}$ after microwave exposure in the $\mathrm{C}$ and $\mathrm{R}$ groups; C-D: $5 \mathrm{~d}$ after microwave exposure in the $\mathrm{C}$ and R groups. Scale bar $=50 \mu \mathrm{m}$. 


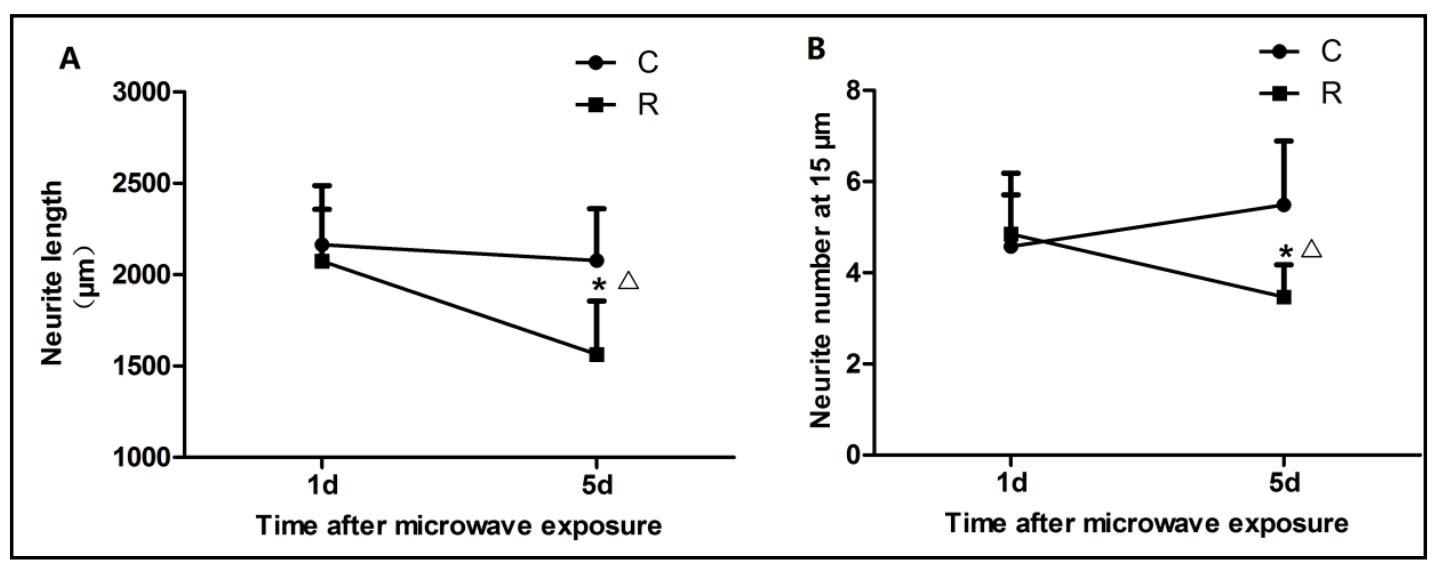

Fig. 3. Lengths and numbers of neurites from hippocampal neurons after microwave exposure. A: the length of neurites 1 and $5 \mathrm{~d}$ after microwave exposure; B: the number of neurites $15 \mu \mathrm{m}$ from the centers of the cell bodies 1 and $5 \mathrm{~d}$ after microwave exposure by the Sholl analysis. $\triangle \mathrm{p}<0.05$ for the whole group effect; ${ }^{*} \mathrm{p}<0.05$ for each time point.

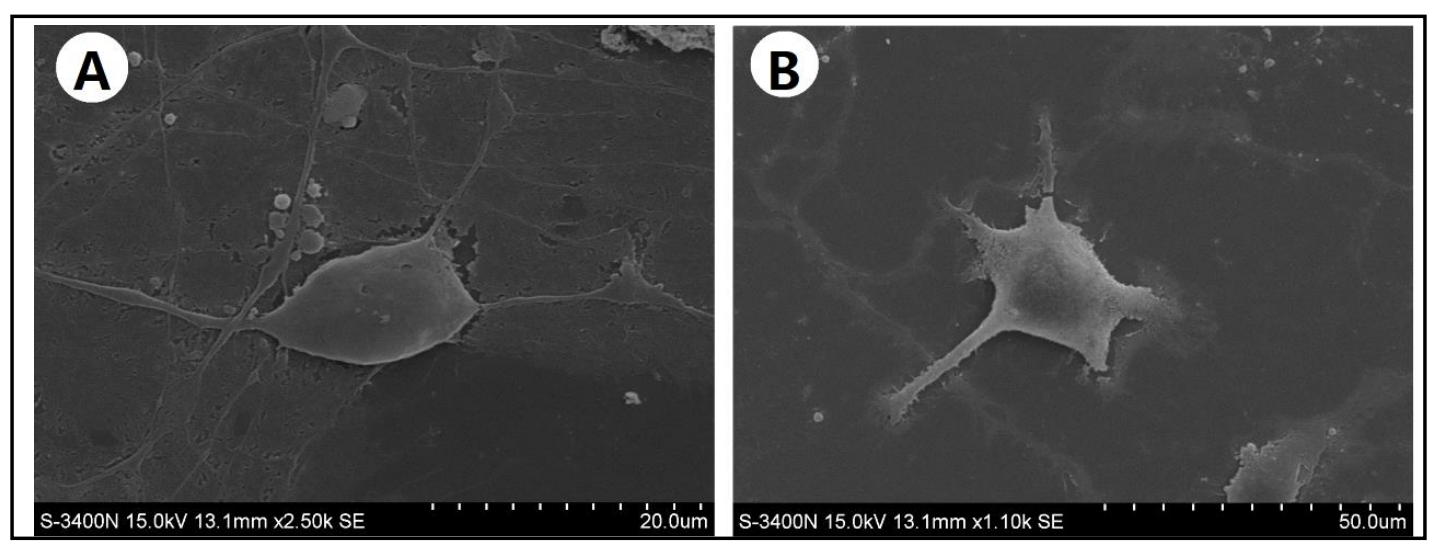

Fig. 4. SEM observation $5 \mathrm{~d}$ after microwave exposure in the $\mathrm{C}$ and $\mathrm{R}$ groups. $\mathrm{A}$ : the $\mathrm{C}$ group, $\mathrm{B}$ : the $\mathrm{R}$ group. Scale bar $=20 \mu \mathrm{m}$ for Fig. $4 \mathrm{~A}$ and $50 \mu \mathrm{m}$ for Fig. 4B.

The mRNA and protein levels of NMDAR subunits decreased after microwave exposure. To determine whether NMDAR participated in the microwave-induced injuries, the mRNA levels of GluN1, 2A and 2B were detected 1, 6, 12 and $24 \mathrm{~h}$ after microwave exposure. For the whole group effect, there were significant differences between the $\mathrm{C}$ and $\mathrm{R}$ groups for the GluN2A and GluN2B mRNA levels (Fig. 5) $(\Delta \mathrm{p}<0.05)$. The relative level of GluN1 decreased significantly at 6 and $12 \mathrm{~h}$ (Fig. 5A) $\left({ }^{*} \mathrm{p}<0.05\right)$. The mRNA level of GluN2A decreased at $12 \mathrm{~h}$ and $24 \mathrm{~h}$ (Fig. 5B) $\left({ }^{*} \mathrm{p}<0.05\right)$. The GluN2B level decreased at 1,6 and $12 \mathrm{~h}$ (Fig. 5C) $\left({ }^{*} \mathrm{p}<0.05\right)$. Because the expression of mRNA occurs earlier than protein synthesis, 6 and $24 \mathrm{~h}$ after microwave exposure were chosen as the detection time points for protein expression. There were significant differences for the protein levels of GluN2A, GluN2B and p- GluN2B for the whole group effect (Fig. 6) ( $\Delta \mathrm{p}<0.05)$. Moreover, statistical analyses were also conducted for each time point. The protein level of GluN2A and $2 \mathrm{~B}$ decreased significantly at $24 \mathrm{~h}$ (Fig. $6 \mathrm{C}$ and D) $\left({ }^{*} \mathrm{p}<0.05\right)$. The $\mathrm{p}$-GluN2B level decreased at 6 and $24 \mathrm{~h}$, demonstrating the early changes in phosphorylation (Fig. 6E) $\left({ }^{*} \mathrm{p}<0.05\right)$. The results of the mRNA and protein levels of key NMDAR subunits indicated the abnormal synthesis of receptor subunits after microwave exposure. 


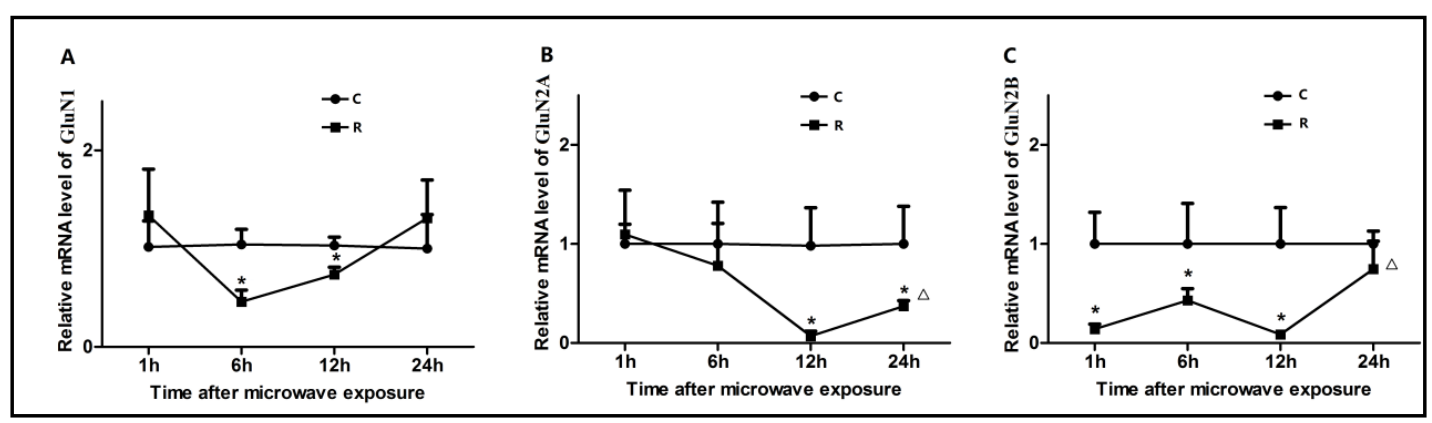

Fig. 5. mRNA levels of GluN1, 2A and 2B after microwave exposure. A-C: relative mRNA levels of GluN1, 2A and $2 \mathrm{~B}$, respectively. ${ }^{\triangle} \mathrm{p}<0.05$ for the whole group effect; ${ }^{*} \mathrm{p}<0.05$ at time point.

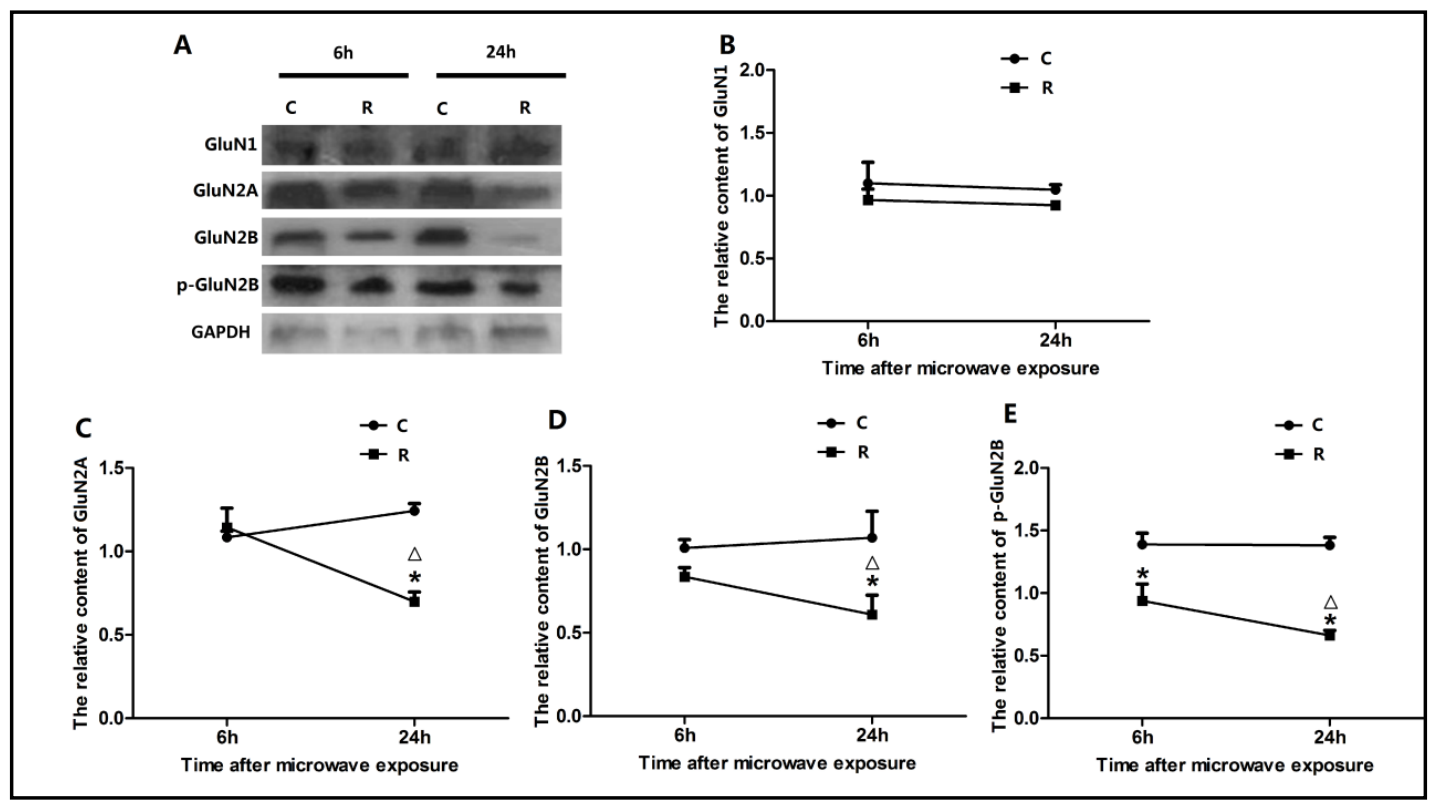

Fig. 6. Protein levels of NMDAR subunits after microwave exposure. A: the protein expression levels of GluN1, 2A, 2B and p-2B; B-E: the statistical results of GluN1, 2A, 2B and p-2B, respectively. $\triangle \mathrm{p}<0.05$ for the whole group effect; ${ }^{*} \mathrm{p}<0.05$ for each time point.

The current density of NMDAR decreased after microwave exposure. The NMDAR current was detected to reflect the receptor activity. Immediately after microwave exposure, whole-cell patch clamp was used to record the NMDAR current. The current amplitude in the $C$ group was $700 \mathrm{pA}$, while the amplitude in the R group was $200 \mathrm{pA}$ (Fig. 7A and B). Compared with the control group, the current density decreased significantly in the radiation group $\left({ }^{*} \mathrm{p}<0.05\right.$, Fig. $\left.7 \mathrm{C}\right)$, indicating reduced NMDAR activity after microwave exposure.

Protective roles of NMDAR in the regulation of microwave-induced synaptic plasticity injuries

The structure recovered after adding NMDA to microwave-induced injured cells. As the structural changes were the most significant $5 \mathrm{~d}$ after microwave exposure, $5 \mathrm{~d}$ after adding the agonist, Dil-staining and SEM observation was performed. Moreover, $5 \mathrm{~d}$ after microwave exposure, the neurites in the $\mathrm{R}$ group were shorter and fewer in number than those in the $\mathrm{C}$ group (Fig. 8A and B). After adding NMDA, the neurites in the C+NMDA and R+NMDA groups showed no significant differences compared to the $\mathrm{C}$ group (Fig. $8 \mathrm{C}$ and $\mathrm{D}$ ). To observe regulatory role of the drug (NMDA) on the microwave-induced structural changes, the four groups, $\mathrm{C}, \mathrm{R}, \mathrm{C}+\mathrm{NMDA}$ and $\mathrm{R}+\mathrm{NMDA}$, were set and the $2 \times 2$ factorial design was applied. 


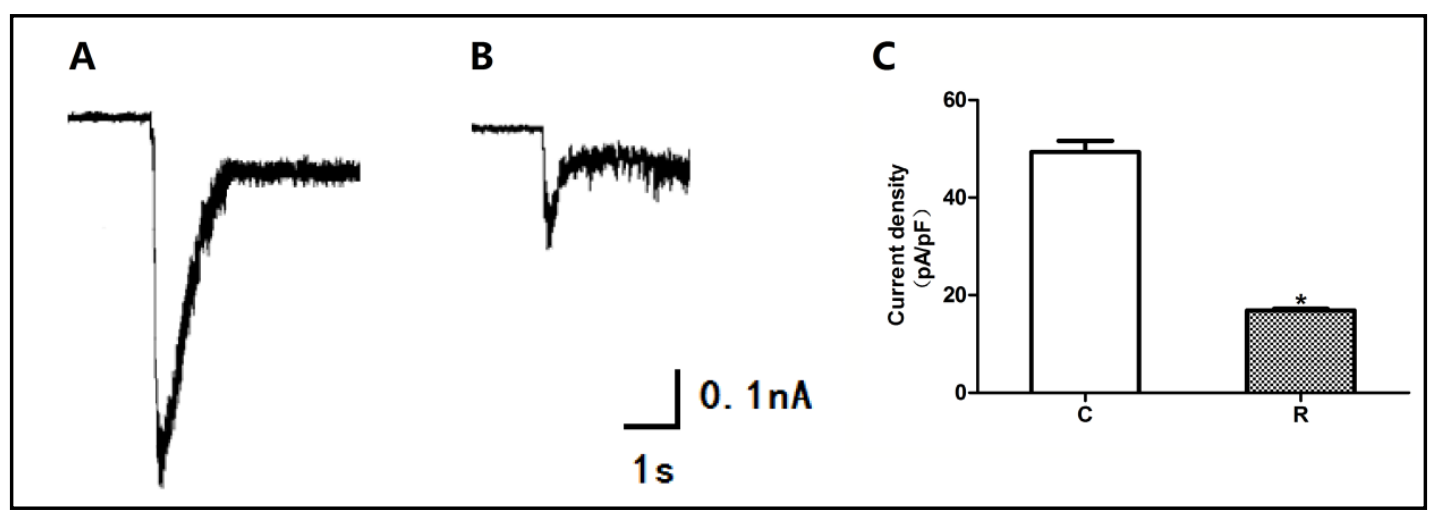

Fig. 7. NMDAR currents immediately after microwave exposure in hippocampal neurons (n=15 per group). A-B: NMDAR currents of the $\mathrm{C}$ and $\mathrm{R}$ groups by whole-cell patch clamp; $\mathrm{C}$ : the current density between the $\mathrm{C}$ and R groups after statistical analysis. ${ }^{*} \mathrm{p}<0.05$.

\begin{abstract}
After the factor and regression analysis, there were no interactions identified between the radiation and drug, and the radiation played the major role in the lengths and number of neurites. After multiple comparisons, compared to the $\mathrm{C}$ group, the lengths and number of neurites in the $\mathrm{R}$ group significantly decreased, while those of the C+NMDA and R+NMDA groups showed no differences (Fig. 9). $\left({ }^{*} \mathrm{p}<0.05\right)$. Compared to the $\mathrm{R}$ group, the neurite lengths of the C, C+NMDA, R+NMDA groups and the neurite numbers of the $\mathrm{C}$ and $\mathrm{C}+\mathrm{NMDA}$ groups showed significant increases $(\Delta \mathrm{p}<0.05)$. Compared to the C+NMDA group, the neurite lengths and number significantly decreased only in the R group ( $\left.{ }^{\#} \mathrm{p}<0.05\right)$. Moreover, the connections between neurons protruded in the $\mathrm{R}$
\end{abstract}
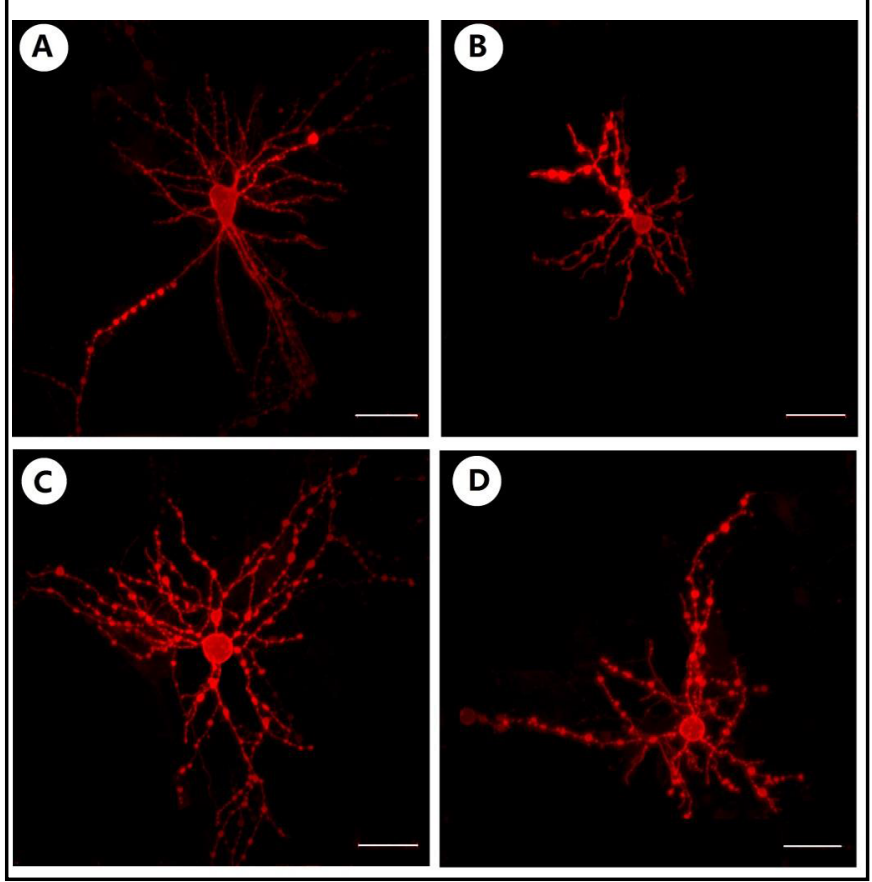

Fig. 8. Structures of primary hippocampal neurons recovered to normal after NMDA treatment. A-D: Dil-staining for the $C, R$, $\mathrm{C}+\mathrm{NMDA}$ and R+NMDA groups. Scale bars $=50 \mu \mathrm{m}$. group, while no breaking changes were found in the other groups (Fig. 10). The structural changes observed in the four groups indicated that radiation could cause decreases in neurite length and number and break neurite connections. NMDA could decrease the occurrence of structural injuries induced by microwave exposure.

Recovery of the TRNA and protein levels of NMDAR subunits after adding NMDA. As the mRNA changes observed for GluN1, 2A and 2B were primarily concentrated $12 \mathrm{~h}$ after microwave radiation, the regulatory role of NMDA was determined at this time point. After the factor analysis, there was an interaction between the radiation and the drug only for the mRNA level of GluN1. No interactions were found between microwave exposure and the addition of NMDA for the mRNA levels of GluN2A and GluN2B. The regression analysis indicated the drug played a major role on the mRNA changes of three subunits. After 


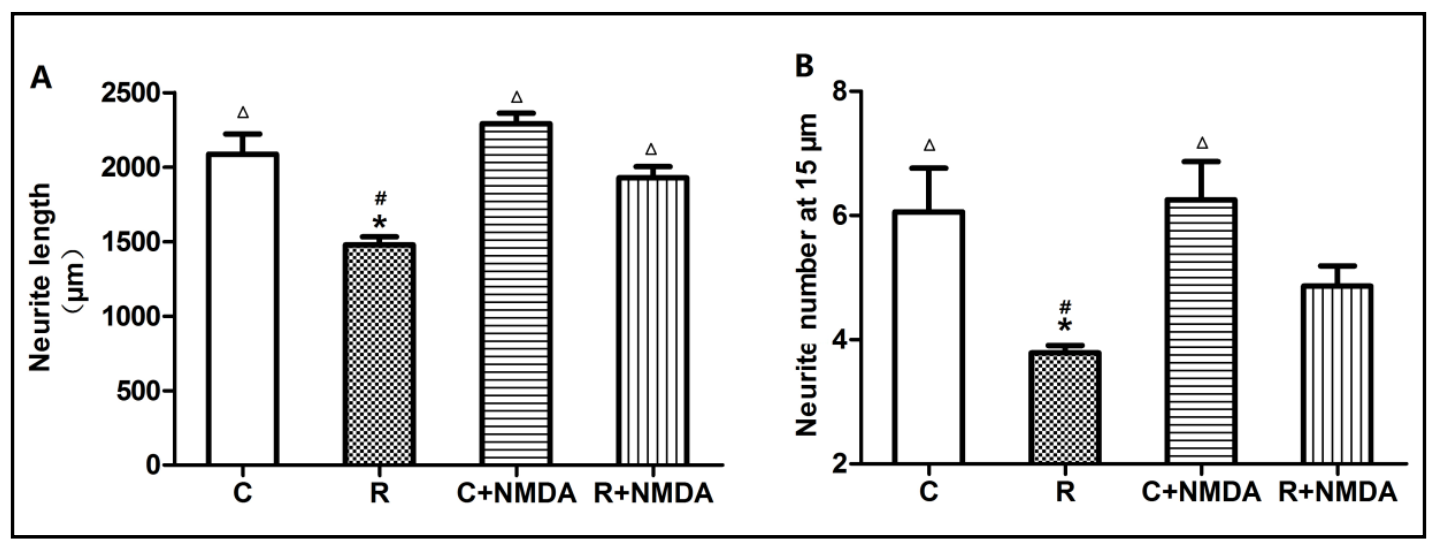

Fig. 9. Lengths and number of neurites $5 \mathrm{~d}$ after microwave exposure and the addition of NMDA. *p $<0.05$ versus the $C$ group, $\Delta \mathrm{p}<0.05$ versus the $\mathrm{R}$ group, ${ }^{*} \mathrm{p}<0.05$ versus the $\mathrm{C}+\mathrm{NMDA}$ group.

Fig. 10. Connections of neurites by the SEM observation. A-D: the C, R, C+NMDA and $\mathrm{R}+\mathrm{NMDA}$ groups. Scale bars $=50$, 30,40 and $50 \mu \mathrm{m}$, respectively, for Fig.s 10 A-D.
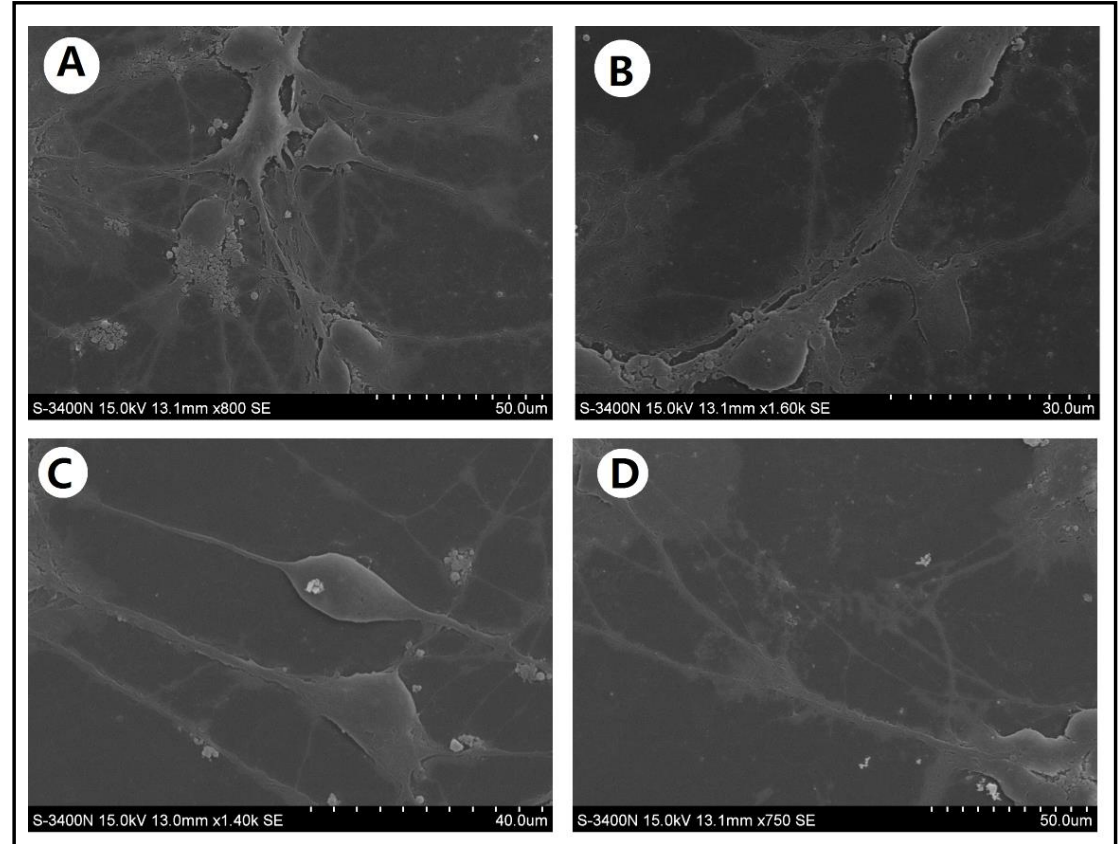

multiple comparisons, the $\mathrm{R}, \mathrm{C}+\mathrm{NMDA}$, and $\mathrm{R}+\mathrm{NMDA}$ groups showed significant differences in the mRNA levels of GluN1 $\left({ }^{*} \mathrm{p}<0.05\right)$ when compared to the $\mathrm{C}$ group. Compared with the $\mathrm{R}$ group, the $\mathrm{C}, \mathrm{C}+\mathrm{NMDA}$, and R+NMDA groups showed significant increases in GluN1 mRNA levels ( $\Delta \mathrm{p}<0.05$ ). When compared with the $\mathrm{C}+\mathrm{NMDA}$ group, the $\mathrm{C}, \mathrm{R}$ and $\mathrm{R}+\mathrm{NMDA}$ groups showed significant differences in the GluN1 mRNA levels ( $\left.{ }^{\#} \mathrm{p}<0.05\right)$. (Fig. 11). For the mRNA levels of GluN2A, the R and C+NMDA groups showed significant differences when compared to the $C$ group $\left({ }^{*} \mathrm{p}<0.05\right)$. When compared to the $\mathrm{R}$ group, the $\mathrm{C}, \mathrm{C}+\mathrm{NMDA}$, and $\mathrm{R}+\mathrm{NMDA}$ groups showed significant increases in the mRNA levels of GluN2A $(\Delta p<0.05)$. Compared with the C+NMDA group, the mRNA level of GluN2A showed differences in the other three groups ( $\left.{ }^{\#} \mathrm{p}<0.05\right)$. (Fig. 11). Compared to the $\mathrm{C}$ group, the mRNA level of GluN2B showed differences in the $\mathrm{R}, \mathrm{C}+\mathrm{NMDA}$, and $\mathrm{R}+\mathrm{NMDA}$ groups $\left({ }^{*} \mathrm{p}<0.05\right)$. When compared with the $\mathrm{R}$ group, there were significant differences in the mRNA levels of GluN2B in the other three groups $(\Delta \mathrm{p}<0.05)$. The GluN2B mRNA level showed significant decreases in the $\mathrm{C}$ and $\mathrm{R}$ groups when compared with the $C+N M D A$ group $\left({ }^{\#} p<0.05\right)$. (Fig. 11). Because the protein changes generally occurred $24 \mathrm{~h}$ after microwave exposure, the detection of the protein levels of GluN1, 2A, 2B and p- GluN2B by Western blot time was set at $24 \mathrm{~h}$ after microwave 
exposure. All results were listed in Fig. 12. After the factor analysis, there was interaction between the radiation and the drug only for the protein level of GluN2B. No interactions were found between microwave exposure and the addition of NMDA for the protein levels of GluN1, GluN2A or p- GluN2B. The regression analysis indicated that the drug played a major role in the protein changes of the four subunits. Multiple comparisons for the GluN1 protein level indicated that there were no significant differences among the four groups. As for GluN2A, the protein levels in the R and C+NMDA groups showed significant differences when compared to the $\mathrm{C}$ group $\left({ }^{*} \mathrm{p}<0.05\right)$. Compared with the $\mathrm{R}$ group, the GluN2A protein levels significantly increased in the other three groups $(\Delta p<0.05)$. Compared with the $\mathrm{C}+\mathrm{NMDA}$ group, there were significant differences in the other three groups for the GluN2A protein level ( $\left.{ }^{\#} \mathrm{p}<0.05\right)$ ). (Fig. 12). Compared to the C group, the GluN2B protein level showed a significant decrease only in the $\mathrm{R}$ group $\left({ }^{*} \mathrm{p}<0.05\right)$. When compared to the $\mathrm{R}$ group, the $\mathrm{C}, \mathrm{C}+\mathrm{NMDA}$ and $\mathrm{R}+\mathrm{NMDA}$ groups showed significant increase for the GluN2B protein level $(\Delta \mathrm{p}<0.05)$. When compared to the $\mathrm{C}+\mathrm{NMDA}$ group, only the $\mathrm{R}$ group showed a significant difference in the GluN2B protein level $\left({ }^{\#} \mathrm{p}<0.05\right)$ (Fig. 12). As for the protein level of $\mathrm{p}$ GluN2B, the R and C+NMDA groups showed significant differences when compared to the $C$ group $\left({ }^{*} \mathrm{p}<0.05\right)$. Compared to the $\mathrm{R}$ group, there were significant differences for the $\mathrm{p}$ GluN2B levels in the other three groups $(\Delta \mathrm{p}<0.05)$. Compared to the $\mathrm{C}+\mathrm{NMDA}$ group, the $\mathrm{C}$ and R group showed significant differences for the level of $p-$ GluN2B $\left({ }^{\#} p<0.05\right)$ (Fig. 12).

The current density of NMDAR showed recovery tends after regulation treatments After microwave exposure, the NMDAR current amplitude decreased. To determine the role of a selective agonist on NMDAR currents, NMDA was added $1 \mathrm{~h}$ before microwave exposure. After the factor analysis, there were interactions between microwave exposure and the addition of NMDA $(p<0.05)$. The regression analysis showed that microwave radiation played a major role. There were significant differences between any of the two groups by the multiple comparisons $\left({ }^{*} \mathrm{p}<0.05, \Delta \mathrm{p}<0.05\right.$, $\left.{ }^{\# \#} \mathrm{p}<0.05\right)$ (Fig. 13). The results indicated that the NMDAR current density recovered but did not recover to the control level.

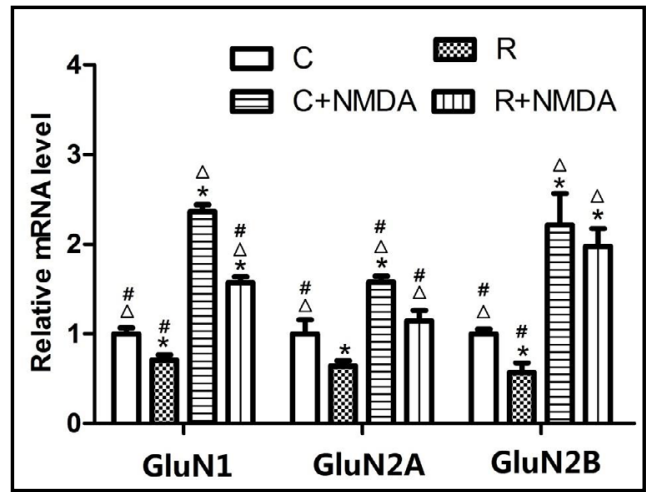

Fig. 11. Relative mRNA levels of GluN1, GluN2A and GluN2B $12 \mathrm{~h}$ after microwave exposure. ${ }^{*} \mathrm{p}<0.05$ versus the $C$ group, $\Delta \mathrm{p}<0.05$ versus the R group, " $\mathrm{p}<0.05$ versus the $\mathrm{C}+\mathrm{NMDA}$ group.

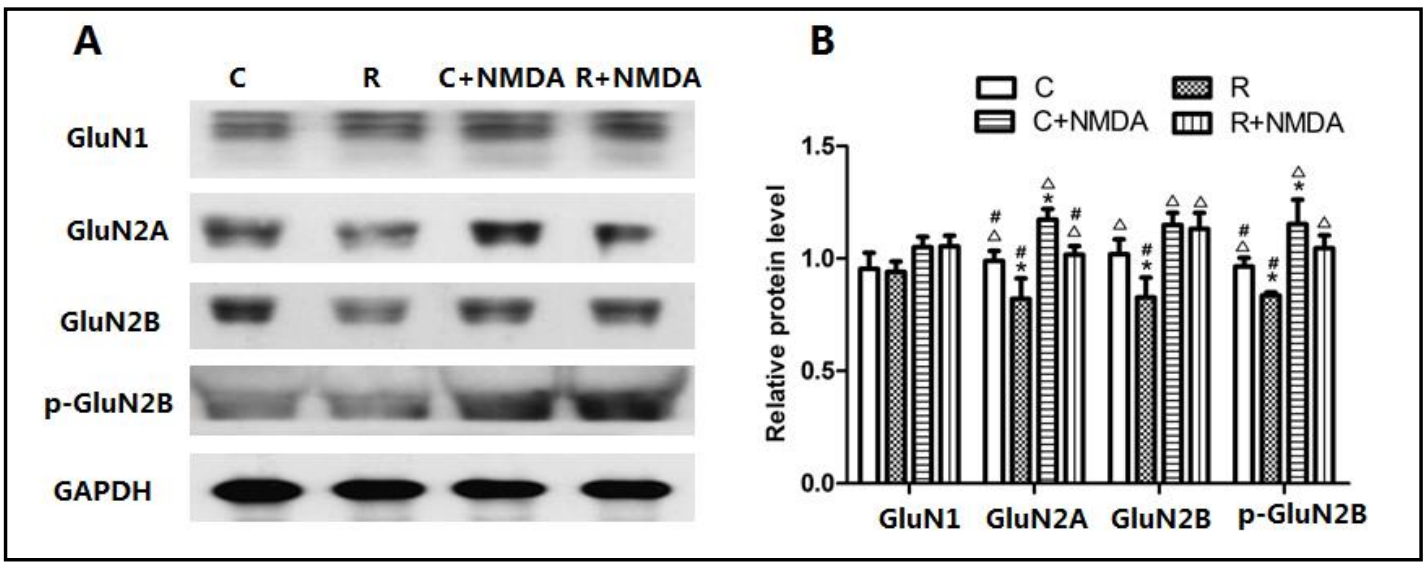

Fig. 12. Protein levels of GluN1, $2 A, 2 B$ and $p-2 B 24$ h after microwave exposure. ${ }^{*} p<0.05$ versus the $C$ group, $\triangle \mathrm{p}<0.05$ versus the $\mathrm{R}$ group, ${ }^{\#} \mathrm{p}<0.05$ versus the $\mathrm{C}+\mathrm{NMDA}$ group. 


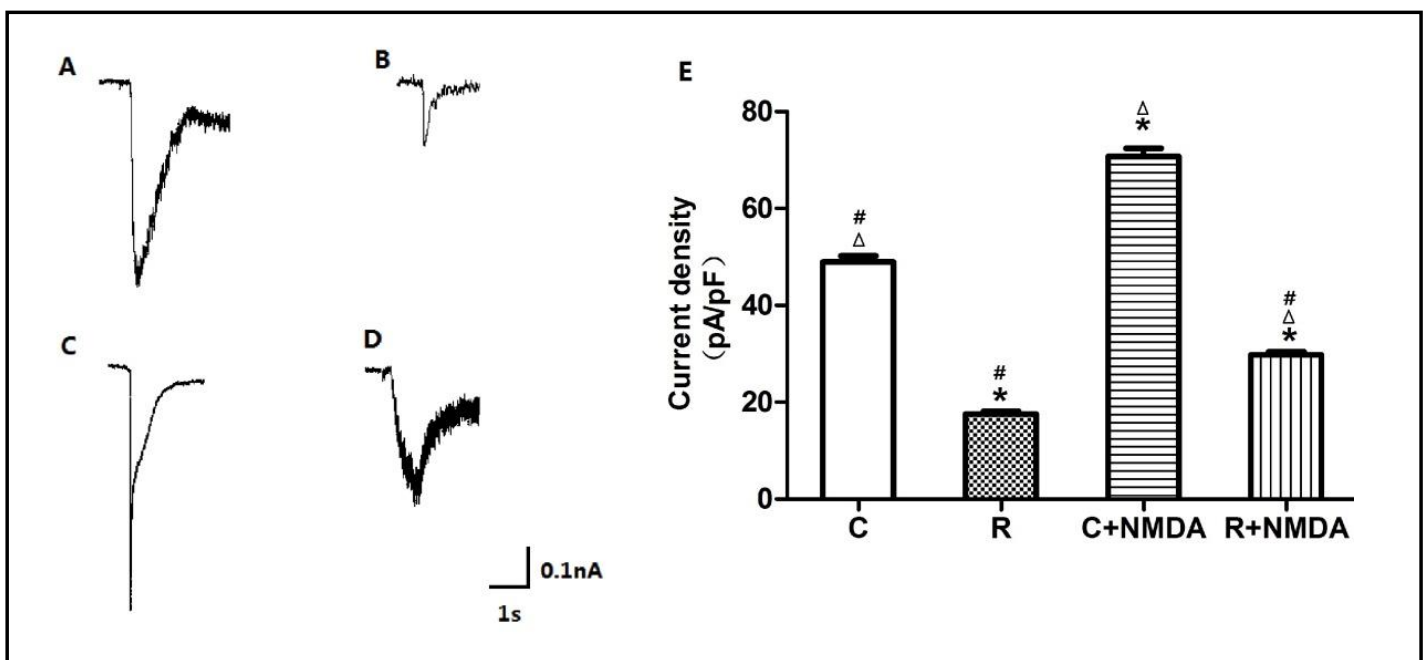

Fig. 13. NMDAR currents changes after the addition of the selective agonist, NMDA. A-D: NMDAR currents for the $\mathrm{C}, \mathrm{R}, \mathrm{C}+\mathrm{NMDA}$ and $\mathrm{R}+\mathrm{NMDA}$ groups, respectively. E: statistical results for the four groups. ${ }^{*} \mathrm{p}<0.05$ versus the $C$ group, ${ }^{\triangle} \mathrm{p}<0.05$ versus the $\mathrm{R}$ group, ${ }^{\#} \mathrm{p}<0.05$ versus the $\mathrm{C}+\mathrm{NMDA}$ group.

\section{Discussion}

Microwave exposure could induce adverse effects, such as headaches and sleep disturbances in humans, the impairment of LTP induction, changes in oxidative stress and neurotransmitter levels, increased blood-brain barrier permeability, and cognitive functional impairment in animals [24-30]. However, the underlying mechanisms of these effects are unclear. The NMDAR plays a central role in development, synaptic plasticity, and neurological disease. The effects of microwave exposure on NMDARs have been studied, indicating that the NMDAR was highly related to microwave-induced neuron impairments. Significant and immediate effects on the binding parameters (Kd and Bmax) of NMDARs were found after acute exposure to $900 \mathrm{MHz}$ electromagnetic fields [8]. Abnormal protein and mRNA expression, as well as posttranslational modifications, were detected in the NMDAR-PSD95CaMKII pathway after microwave exposure, and a GluN2B subunit gene promoter region variant was associated with microwave-induced neuron impairment [31, 32]. However, further studies on hippocampal neurons regarding the effects of microwave exposure on NMDAR subunits and activity have been limited. In this study, we aimed to determine the effects of microwave radiation on the subunit composition and activity of NMDARs and their relationship with microwave-induced synaptic plasticity.

Our research group once used a $2.856 \mathrm{GHz}$ pulsed microwave at different power densities of $0,5,10$ and $50 \mathrm{~mW} / \mathrm{cm}^{2}$ to expose Wistar rats and found that the 10 and 50 $\mathrm{mW} / \mathrm{cm}^{2}$ microwave exposure could induce deficits in spatial learning and memory, LTP impairment and structural injuries [29]. Based on this study, we focused on the effects and mechanism of the $50 \mathrm{~mW} / \mathrm{cm}^{2}$ microwave exposure and conducted a study examining the relationship between NMDARs and microwave-induced learning and memory impairment through the long-term observation of Wistar rats $(18 \mathrm{~m})$ after microwave exposure [6]. The observed changes in NMDAR subunits attracted our attention. Therefore, we conducted further research on the NMDAR and attempted to reveal the underlying mechanism at the cellular level after the $50 \mathrm{~mW} / \mathrm{cm}^{2}$ microwave exposure.

Microwave radiation can cause the synaptic plasticity injuries, including LTP impairment and alterations to the structure and quantity of synapses and amino acid changes in the rat hippocampus and in PC12 cells [20, 22]. However, there has been research showing that microwave radiation did not affect the ability of neurons to develop LTP in response to tetanus or to retain a potentiated state [33]. There have been differences between reports 
from different laboratories. Therefore, to reveal the mechanism underlying microwave exposure, it was necessary to establish a reliable cell model with synaptic plasticity injuries. In our study, we used $50 \mathrm{~m} / \mathrm{cm}^{2}$ microwave to expose primary hippocampal neurons and observed the structural and functional changes to evaluate the success of the cell model. After microwave radiation, impairments in neurite development were observed, including decreased lengths and numbers of neurites, and even the presence of proximal fractures. The above changes indicated structural and functional abnormalities of synaptic plasticity and the successful establishment of the cell model.

The NMDAR, a type of glutamate-gated ion channel, is crucial for neuronal communication and synaptic plasticity and has been a hot topic in neuroscience fields [34]. Wang LF [31] detected abnormal protein and mRNA expression, as well as posttranslational modifications, in the NMDAR-PSD95-CaMKII pathway and its associated components, such as synapsin I, following the microwave radiation exposure of rats and PC12 cells. In another study, a novel rat GluN2B subunit gene promoter region variant was associated with microwave-induced neuron impairment [32]. The previous studies indicated that the NMDAR was highly related to the microwave-induced neuron impairments. However, further studies on hippocampal neurons and on the NMDAR subunits and activity were limited. In our study, decreases in the mRNA and protein levels of GluN2A and GluN2B were found. The decreases in the pGluN2B expression level and the NMDAR current densities both indicated the weakness of the NMDAR activity.

Studies have found that dendrite arbor growth, or dendritogenesis, is choreographed by a diverse set of cues, including the GluN2A and GluN2B NMDAR subunits. While the GluN1/ GluN2B receptors are predominantly expressed in immature neurons and promote plasticity, GluN1/GluN2B receptors are primarily expressed in mature neurons and induce circuit stability [35]. Moreover, the autophosphorylated CaMKII binds directly to NMDAR subunits, colocalizes with NMDARs in the postsynaptic density, and phosphorylates GluN2B subunits at Ser1303 [36]. In our study, the mRNA and protein expression levels of GluN2A and GluN2B decreased, and the protein level of p-NR2B (Ser 1303) also decreased, which indicated that microwave exposure might impair the development of immature and mature neurons and the activation of NMDARs. Based on these experimental results, we can provide more direct and sufficient evidence regarding the effects of microwave radiation on NMDARs. However, the relationship between NMDARs and microwave-induced synaptic plasticity injuries requires further study.

Because the expression level and activity of NMDARs decreased after microwave exposure, the agonist, NMDA, was added to examine NMDAR regulation. Shamloo [37] once studied the toxicity of NMDA by adding $50 \mu \mathrm{M}$ NMDA to primary neuronal cultures for $1 \mathrm{~h}$ and found excitotoxic changes. Therefore, in our experiment the $30 \mu \mathrm{M}$ NMDA was added for $1 \mathrm{~h}$, which was lower than the excitotoxic concentration. After adding NMDA, we found changes in the neurites, NMDAR subunits expression levels and NMDAR currents in the R+NMDA group that trended toward recovery, which indicated the protective roles of NMDARs on microwave-induced synaptic plasticity injuries.

The neuronal structure is the basis for neuronal functional development. Studies have found that neuronal networks are the substrate of learning and memory and that the balancing of synaptic structures was a hallmark for the stabilization of structural modifications during synaptic plasticity [38-40]. Neuronal activity regulates brain development and synaptic plasticity through NMDARs, and the structural modifications were related to NMDARs [4143]. Specifically, after adding NMDA, the neurites in the R+NMDA group basically recovered to normal $5 \mathrm{~d}$ after microwave exposure. Moreover, the breaks in neurite connections disappeared in the R+NMDA group. In the statistical analysis, there were no interactions between the radiation and drug, and the radiation played the major role on the length and number of neurites. The results indicated that microwave radiation was the major factor for the structural changes and that NMDA could reduce the microwave-induced structural injuries.

\section{KARGER}




\section{Cellular Physiology Cell Physiol Biochem 2018;51:97-112

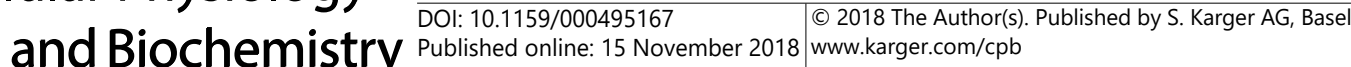 \\ Wang et al.: Effects of Microwave on Synaptic Plasticity and NMDAR}

After adding NMDA, no interactions were found between microwave exposure and the addition of NMDA for the mRNA levels of GluN2A, GluN2B and the protein levels of GluN1, $2 \mathrm{~A}$ and $\mathrm{p}-\mathrm{GluN2B}$. The regression analysis indicated that the drug played a major role in the mRNA and protein changes of the four subunits. One possible reason is that the expression levels of NMDAR subunits are more sensitive to the agonist. Compared to the $C$ group, the expression levels of GluN2A, 2B and p- GluN2B showed no differences in the R+NMDA group, indicating that the addition of NMDA can restore the NMDAR subunit expression levels to normal levels, which were originally reduced by microwave radiation.

The whole cell patch clamp technique is essential for understanding the external factors that affect ligand-gated ion channel function, cell physiology, and the nervous system under normal or pathological conditions. NMDAR is an ionotropic glutamate receptor that exhibits a voltage-dependent $\mathrm{Mg}^{2+}$ block, is highly $\mathrm{Ca}^{2+}$ permeable, and deactivates slowly. These properties contribute to the importance of NMDARs to cell survival, synaptic plasticity, and many forms of learning and memory [23, 44, 45]. The patch clamp experiment found that microwave radiation could induce a decrease in the NMDAR current, and the current recovered after preincubation with NMDA in the R+NMDA group. These results indicated that the NMDAR agonist could decrease the microwave-induced current changes.

\section{Conclusion}

In summary, we believe that microwave radiation can cause neuronal synaptic plasticity injuries. Adding NMDA, the selective agonist of NMDAR, could reduce microwave-induced synaptic plasticity injuries, including structural changes, the expression levels of NMDAR subunits and NMDAR activity. Therefore, we speculate that the decreases observed in mRNA and protein levels for GluN1, GluN2A, and GluN2B and the substantial decrease observed for the NMDAR current density might be the underlying reasons that microwave exposure induces synaptic plasticity injuries. With the rapid development of microwave connected applications, people are increasingly exposed to microwaves. Microwaves could decrease the subunit expression levels and the NMDAR current density, which might be a useful tool for some NMDAR excitotoxicity-related diseases due to its essential roles in synapse formation and neuronal development.

\section{Acknowledgements}

Hui Wang and Shengzhi Tan conceived the experiments and wrote the paper. Binwei Yao, Xinping Xu, Bo Zhang and Jing Zhang analysed the SEM, PCR and WB data. Hongmei Zhou conducted the microwave irradiation. Ruiyun Peng designed the study. All the authors had reviewed the manuscript. This work was supported by grants from the National Natural Science Foundation of China (General Grant No. 61401497 and No. 31570847) and the Innovation Foundation of the Academy of Military Medical Sciences (2017CXJJ17). The authors would like to offer special thanks to the editor and referees for their comments and suggestions, which greatly improved the substance and presentation of the paper.

\section{Disclosure Statement}

The authors declare to have no competing interests. 


\section{Cellular Physiology Cell Physiol Biochem 2018;51:97-112 and Biochemistry \begin{tabular}{l|l} 
DOI: 10.1159/000495167 & (c) 2018 The Author(s). Published by S. Karger AG, Basel \\
www.karger.com/cpb
\end{tabular}

Wang et al.: Effects of Microwave on Synaptic Plasticity and NMDAR

\section{References}

1 Deshmukh PS, Nasare N, Megha K, Banerjee BD, Ahmed RS, Singh D, Abegaonkar MP, Tripathi AK, Mediratta PK: Cognitive Impairment and Neurogenotoxic Effects in Rats Exposed to Low-Intensity Microwave Radiation. Int J Toxicol 2015;34:284-290.

-2 Altunkaynak BZ, Altun G, Yahyazadeh A, Kaplan AA, Deniz OG, Turkmen AP, Onger ME, Kaplan S: Different methods for evaluating the effects of microwave radiation exposure on the nervous system. Journal of chemical neuroanatomy 2016;75:62-69.

-3 Shahin S, Banerjee S, Singh SP, Chaturvedi CM: $2.45 \mathrm{GHz}$ Microwave Radiation Impairs Learning and Spatial Memory via Oxidative/Nitrosative Stress Induced p53-Dependent/Independent Hippocampal Apoptosis: Molecular Basis and Underlying Mechanism. Toxicol Sci 2015;148:380-399.

4 Lau CG, Zukin RS: NMDA receptor trafficking in synaptic plasticity and neuropsychiatric disorders. Nature Reviews Neuroscience 2007;8:413-426.

5 Köhr G: NMDA receptor function: subunit composition versus spatial distribution. Cell and Tissue Research 2006;326:439-446.

6 Wang H, Peng R, Zhao L, Wang S, Gao Y, Wang L, Zuo H, Dong J, Xu X, Zhou H, Su Z: The relationship between NMDA receptors and microwave-induced learning and memory impairment: a long-term observation on Wistar rats. Int J Radiat Biol 2015;91:262-269.

7 Xu S, Ning W, Xu Z, Zhou S, Chiang H, Luo J: Chronic exposure to GSM 1800-MHz microwaves reduces excitatory synaptic activity in cultured hippocampal neurons. Neurosci Lett 2006;398:253-257.

$>8$ Mausset-Bonnefont AL, Hirbec H, Bonnefont X, Privat A, Vignon J, de Seze R: Acute exposure to GSM 900-MHz electromagnetic fields induces glial reactivity and biochemical modifications in the rat brain. Neurobiol Dis 2004; 17:445-454.

-9 Liu L, Wong TP, Pozza MF, Lingenhoehl K, Wang Y, Sheng M, Auberson YP, Wang YT: Role of NMDA receptor subtypes in governing the direction of hippocampal synaptic plasticity. Science 2004;304:1021-1024.

-10 Barria A, Malinow R: NMDA receptor subunit composition controls synaptic plasticity by regulating binding to CaMKII. Neuron 2005;48:289-301.

11 Volianskis A, France G, Jensen MS, Bortolotto ZA, Jane DE, Collingridge GL: Long-term potentiation and the role of N-methyl-d-aspartate receptors. Brain Res 2015;1:1-12.

12 Staffend NA, Meisel RL: DiOlistic labeling in fixed brain slices: phenotype, morphology, and dendritic spines. Curr Protoc Neurosci 2011;Chapter 2:Unit 213.

13 Hough LH, Brown ME: Labeling of neuronal morphology using custom diolistic techniques. J Neurosci Methods 2017;282:43-51.

14 Villarroya O, Ballestin R, Lopez-Hidalgo R, Mulet M, Blasco-Ibanez JM, Crespo C, Nacher J, Gilabert-Juan J, Varea E: Morphological alterations in the hippocampus of the Ts65Dn mouse model for Down Syndrome correlate with structural plasticity markers. Histol Histopathol 2017;10.14670/HH-11-89411894.

15 Kramer B, Tropitzsch A, Muller M, Lowenheim H: Myelin-induced inhibition in a spiral ganglion organ culture - Approaching a natural environment in vitro. Neuroscience 2017;10.1016/j. neuroscience.2017.05.053.

16 Traynelis SF, Wollmuth LP, McBain CJ, Menniti FS, Vance KM, Ogden KK, Hansen KB, Yuan H, Myers SJ, Dingledine R: Glutamate receptor ion channels: structure, regulation, and function. Pharmacol Rev 2010;62:405-496.

17 Cull-Candy SG, Leszkiewicz DN: Role of distinct NMDA receptor subtypes at central synapses. Sci STKE 2004;2004:re16.

18 Raveendran R, Devi Suma Priya S, Mayadevi M, Steephan M, Santhoshkumar TR, Cheriyan J, Sanalkumar R, Pradeep KK, James J, Omkumar RV: Phosphorylation status of the NR2B subunit of NMDA receptor regulates its interaction with calcium/calmodulin-dependent protein kinase II. J Neurochem 2009;110:92105.

19 Shen H, Pan J, Pan L, Zhang N: TRPC6 inhibited NMDA current in cultured hippocampal neurons. Neuromolecular Med 2013;15:389-395.

-20 Wang H, Peng R, Zhou H, Wang S, Gao Y, Wang L, Yong Z, Zuo H, Zhao L, Dong J, Xu X, Su Z: Impairment of long-term potentiation induction is essential for the disruption of spatial memory after microwave exposure. Int J Radiat Biol 2013;89:1100-1107. 


\section{Cellular Physiology Cell Physiol Biochem 2018:51:97-112 and Biochemistry \begin{tabular}{l|l} 
DOI: 10.1159/000495167 & (c) 2018 The Author(s). Published by S. Karger AG, Basel \\
wublished
\end{tabular}

Wang et al.: Effects of Microwave on Synaptic Plasticity and NMDAR

21 Nancy ASR, L. M: DiOlistic labeling of neurons in tissue slices: a qualitative and quantitative analysis of methodological variations. Frontiers in Neuroanatomy 2011;5:1-14.

-22 Xiong L, Sun CF, Zhang J, Gao YB, Wang LF, Zuo HY, Wang SM, Zhou HM, Xu XP, Dong J, Yao BW, Zhao L, Peng RY: Microwave Exposure Impairs Synaptic Plasticity in the Rat Hippocampus and PC12 Cells through Overactivation of the NMDA Receptor Signaling Pathway. Biomed Environ Sci 2015;28:13-24.

-23 Zhang YF, Li X, Peng LL, Wang GH, Ke KF, Jiang ZL: Novel glycine-dependent inactivation of NMDA receptors in cultured hippocampal neurons. Neurosci Bull 2012;28:550-560.

-24 Hossmann KA, Hermann D: Effects of electromagnetic radiation of mobile phones on the central nervous system. Bioelectromagnetics 2003;24:49-62.

-25 Salford LG, Brun AE, Eberhardt JL, Malmgren L, Persson BR: Nerve cell damage in mammalian brain after exposure to microwaves from GSM mobile phones. Environmental Health Perspectives 2003;111:881-883.

-26 D'Andrea JA, Chou C, Johnston SA, Adair ER: Microwave effects on the nervous system. Bioelectromagnetics 2003;24:S107-S147.

27 Murbach M, Christopoulou M, Crespo - Valero P, Achermann P, Kuster N: Exposure system to study hypotheses of ELF and RF electromagnetic field interactions of mobile phones with the central nervous system. Bioelectromagnetics 2012;33:527-533.

28 Jing J, Yuhua Z, Xiao-qian Y, Rongping J, Dong-mei G, Xi C: The influence of microwave radiation from cellular phone on fetal rat brain. Electromagnetic Biology and Medicine 2012;31:57-66.

29 Wang H, Peng R, Zhou H, Wang S, Gao Y, Wang L, Yong Z, Zuo H, Zhao L, Dong J: Impairment of long-term potentiation induction is essential for the disruption of spatial memory after microwave exposure. International Journal of Radiation Biology 2013;89:1100-1107.

30 Maaroufi K, Had-Aissouni L, Melon C, Sakly M, Abdelmelek H, Poucet B, Save E: Spatial learning, monoamines and oxidative stress in rats exposed to $900 \mathrm{MHz}$ electromagnetic field in combination with iron overload. Behavioural Brain Research 2014;258:80-89.

-31 Wang LF, Wei L, Qiao SM, Gao XN, Gao YB, Wang SM, Zhao L, Dong J, Xu XP, Zhou HM, Hu XJ, Peng RY: Microwave-Induced Structural and Functional Injury of Hippocampal and PC12 Cells Is Accompanied by Abnormal Changes in the NMDAR-PSD95-CaMKII Pathway. Pathobiology 2015;82:181-194.

-32 Wang LF, Tian DW, Li HJ, Gao YB, Wang CZ, Zhao L, Zuo HY, Dong J, Qiao SM, Zou Y, Xiong L, Zhou HM, Yang YF, Peng RY, Hu XJ: Identification of a Novel Rat NR2B Subunit Gene Promoter Region Variant and Its Association with Microwave-Induced Neuron Impairment. Mol Neurobiol 2016;53:2100-2111.

-33 Pakhomov AG, Doyle J, Stuck BE, Murphy MR: Effects of high power microwave pulses on synaptic transmission and long term potentiation in hippocampus. Bioelectromagnetics 2003;24:174-181.

-34 Bannerman DM, Sprengel R, Sanderson DJ, McHugh SB, Rawlins JN, Monyer H, Seeburg PH: Hippocampal synaptic plasticity, spatial memory and anxiety. Nat Rev Neurosci 2014;15:181-192.

-35 Bustos FJ, Jury N, Martinez P, Ampuero E, Campos M, Abarzua S, Jaramillo K, Ibing S, Mardones MD, Haensgen H, Kzhyshkowska J, Tevy MF, Neve R, Sanhueza M, Varela-Nallar L, Montecino M, van Zundert B: NMDA receptor subunit composition controls dendritogenesis of hippocampal neurons through CAMKII, CREB-P, and H3K27ac. J Cell Physiol 2017;10.1002/jcp.25843.

-36 Sessoms-Sikes S, Honse Y, Lovinger DM, Colbran RJ: CaMKIIalpha enhances the desensitization of NR2Bcontaining NMDA receptors by an autophosphorylation-dependent mechanism. Mol Cell Neurosci 2005;29:139-147.

-37 Shamloo M, Soriano L, Wieloch T, Nikolich K, Urfer R, Oksenberg D: Death-associated protein kinase is activated by dephosphorylation in response to cerebral ischemia. J Biol Chem 2005;280:42290-42299.

-38 Bailey CH, Kandel ER, Harris KM: Structural Components of Synaptic Plasticity and Memory Consolidation. Cold Spring Harb Perspect Biol 2015;7:a021758.

39 Meyer D, Bonhoeffer T, Scheuss V: Balance and stability of synaptic structures during synaptic plasticity. Neuron 2014;82:430-443.

40 Knoblauch A, Korner E, Korner U, Sommer FT: Structural synaptic plasticity has high memory capacity and can explain graded amnesia, catastrophic forgetting, and the spacing effect. PLoS One 2014;9:e96485.

41 Sanders EM, Nguyen MA, Zhou KC, Hanks ME, Yusuf KA, Cox DN, Dumas TC: Developmental modification of synaptic NMDAR composition and maturation of glutamatergic synapses: matching postsynaptic slots with receptor pegs. Biol Bull 2013;224:1-13. 


\section{Cellular Physiology Cell Physiol Biochem 2018;51:97-112

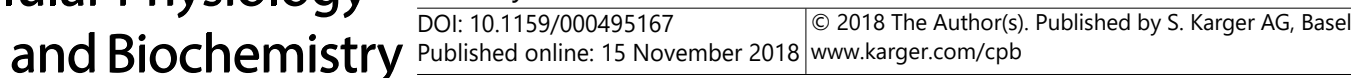

Wang et al.: Effects of Microwave on Synaptic Plasticity and NMDAR

42 George J, Baden DG, Gerwick WH, Murray TF: Bidirectional influence of sodium channel activation on NMDA receptor-dependent cerebrocortical neuron structural plasticity. Proc Natl Acad Sci U S A 2012;109:19840-19845.

43 Oh WC, Hill TC, Zito K: Synapse-specific and size-dependent mechanisms of spine structural plasticity accompanying synaptic weakening. Proc Natl Acad Sci U S A 2013;110:E305-312.

\$4 Lee KY, Chung HJ: NMDA receptors and L-type voltage-gated Ca channels mediate the expression of bidirectional homeostatic intrinsic plasticity in cultured hippocampal neurons. Neuroscience 2014;10.1016/j.neuroscience.2014.07.038.

-45 Glasgow NG, Johnson JW: Whole-cell patch-clamp analysis of recombinant NMDA receptor pharmacology using brief glutamate applications. Methods Mol Biol 2014;1183:23-41. 